\title{
Governing and accelerating transformative entrepreneurship: exploring the potential for small business innovation on urban sustainability transitions.
}

\author{
Sarah Burch \\ University of Waterloo \\ Mark Andrachuk \\ University of Waterloo \\ Dustin Carey \\ University of Waterloo \\ Niki Frantzeskaki \\ Erasmus University, Rotterdam \\ Heike Schroeder \\ University of East Anglia \\ Niklas Mischkowski \\ Erasmus University, Rotterdam \\ Derk Loorbach \\ Erasmus University, Rotterdam
}

\begin{abstract}
The alluring yet nebulous concept of transformative change is increasingly gaining traction in conversations about pathways to more sustainable futures and responses to climate change. This shift in focus from incremental change to potentially radical experiments in sustainability at multiple levels of governance suggests that new conceptual tools are needed to illuminate new types of actors, interests, and capacities at play. This paper draws upon a diverse suite of theoretical tools, derived from multi-level governance theory, sustainability transitions scholarship, and sustainability entrepreneurship literature, to interrogate the transformative potential of small and medium-sized enterprises (SMEs) in the context of urban sustainability transitions/transformations. SMEs are an often overlooked, albeit potentially significant group of actors. Through a systematic literature review we (1) identify characteristics of SMEs that might make them relatively more able and likely to produce radical innovations, (2) explore dimensions of the broader socio-political context that influence the likelihood of this potential for innovation to be translated into action in urban spaces, and (3) discuss implications of these dynamics for transformative sustainability governance.
\end{abstract}

Acknowledgements:

The authors would like to thank the Canadian Social Sciences and Humanities Research Council for generous financial support of this research, and the peer reviewers for their thoughtful comments. 


\section{Introduction}

Scholars from diverse disciplines have argued that proactive governance is needed for societal transformation [1,2]. Proactive governance requires new understandings of transformation dynamics [3-6]. This is particularly true in the case of climate change mitigation and adaptation [7], as evidence of rapid warming accumulates and the prospect of stranded assets looms [8]. As 0'Brien [9] has argued, approaches aimed at societal transformation need to contest the status quo and create alternatives, in addition to accommodating unavoidable global environmental change. Urban spaces have been identified as promising contexts within which these alternatives to the status quo might emerge, given the coincident challenges (and opportunities) presented by transportation, energy provision, buildings, waste management, and land use planning $[10,11]$.

Theories of sustainability transitions, multi-level governance, and sustainability entrepreneurship shed light on the issues of societal transformation, and together contribute to a more nuanced picture of community-level innovation. In drawing these domains together, we respond to the over-arching objective of deepening and expanding the concept of sustainability governance as a lens for considering multiple actors (and actions) at multiple levels that ultimately add up to larger scale systemic changes in society. Following this view, urban innovation is a multi-actor and multiscale process that contributes to transformations. While it is widely acknowledged that individual action alone will be insufficient to address the challenge of rapid decarbonization, government cannot control the potentially disruptive societal transformations as they are the outcomes of multifaceted interactions between agency and structure. So while no one actor can steer transitions in a classical sense, all actors influence the speed and direction of transitions in some way. This is especially true in the case of small businesses - an under-examined but crucial source of both emissions and innovative sustainability solutions $[12,13]$.

In this paper we gather together leading research that explores the roles small- and medium-sized enterprises are actively playing in sustainability transitions, and the aspects of governance that are required to support small and medium-sized enterprises (SMEs) for sustainability transitions in urban spaces. The aim of this synthesis is to inform future research in the intersecting domains of sustainability science and earth system governance.

\section{Governing sustainability transitions}

Biermann et al. [14] define governance as "the interrelated and increasingly integrated system of formal and informal rules, rule-making systems, and actornetworks at all levels of human society (from local to global) that are set up to steer societies towards preventing, mitigating and adapting to global and local environmental change." This orientation places an emphasis on multi-level 
interactions, human interconnections, and the normative ideal of avoiding harm. Pereira et al. [6] describe the development of transitions governance as a means of understanding the conditions and contexts that lead to sustainable outcomes [see also $15,16,17]$. As such, transitions governance focuses on agency that actively pursues sustainability transitions as a normative agenda. Although much attention has gone towards the importance of devising policy and network arrangements that support sustainability transitions $[15,16]$, the transitions literature rarely emphasize the importance of, and role for, private sector agency in sustainability governance [18].

A useful entry point to bring together SMEs and sustainability transitions is to think about governance contexts. Lemos and Agrawal [19] describe governance arrangements as comprised of the state, communities, and markets. The state interacts with communities through co-management, and with markets through public-private partnerships. Private-social partnerships, such as payment for ecosystem services, forge links between communities and markets, in this view [19]. This framing helps highlight the importance of each domain and the interrelationships between them. When this framing is applied to the governance of sustainability transitions, we see markets and the private sector as an important operational domain where changes need to take effect (i.e., carbon reductions), and as a source of innovation.

The economy and private sector have been recognized as important arenas for research, yet little empirical work has been conducted [for commentary see 6, 20] that sufficiently characterizes the varied motivations, capacities, and transformative potential of small businesses. In particular, a dearth of scholarship exists that explicitly addresses the potential for small businesses to play a significant role in sustainability transitions, the coordination and governance challenge that this presents, and the unique characteristics of urban spaces (such as geographic scale, entrepreneurship culture, governance scale, and 'retail' or deeply communityoriented politics) that might enable or inhibit innovation on the part of small businesses. The section that follows more deeply explores the capacities and motivations of SMEs, with the goal of uncovering ways to adapt urban governance models and accelerate sustainability transitions.

\section{Small businesses as sustainability entrepreneurs: characteristics and motivations}

SMEs make up the majority of global business firms, typically comprising more than 95\% of businesses in countries such as the US and UK [21-23]. As a result, SMEs are collectively responsible for a large proportion of global environmental stresses. SMEs are estimated to collectively produce around $70 \%$ of the total global pollution and $60 \%$ of total carbon emissions, suggesting that the sum total of SMEs' environmental impacts outweighs the combined environmental impact of large firms [24, 25]. Consequentially, there is a clear impetus to engage SMEs with the 
intention of encouraging environmental improvements of operations and promoting sustainability entrepreneurship.

At the European Union level, for instance, the discussion of open innovation points at the ways SMEs and cities collaborate in the making of sustainable resilient cities, calling for stronger partnerships between them as well as for new types of partnerships between SMEs and researchers. Involving SMEs as urban change agents in planning processes in cities with the aim to co-produce disruptive innovations is a daring sustainability approach and not easily adopted by cities on the ground. Involving SMEs needs to be an informed decision that considers their potential, characteristics and vulnerabilities as well as the caveats such a process may entail.

\subsection{Deconstructing SMEs' capacity to innovate on sustainability}

The simple characterization of business (or SMEs ${ }^{1}$ ) as a unitary actor is, problematic [27], and, indeed, culturally informed economic geographers [28], for instance, would examine the varied motivations of small businesses as embedded in broader social, economic, and biophysical contexts. In the language of sustainability (or sociotechnical) transitions, both actors and sustainable technologies are not exogenous to 'landscape' level trajectories [cf. 29, 30-32] or the underlying development path $[10,33,34]$ : the powerful contextual factors that are emergent, imbued with inertia, and beyond the control of any single set of actors or rules.

SMEs are understood to be flexible firms, able to act nimbly to fill local or specialized market and technology niche markets since they are less encumbered by existing organizational structures that predate sustainability as a factor in enterprise performance [35-39]. As a result, SMEs may be better able to quickly capitalize on innovative and sustainable practices and navigate the multi-level governance context of cities in order to scale these sustainable practices. This is a result of the increased involvement of owner/managers within the day-to-day operations, relatively small organizational structure, and strategic vision of SMEs, allowing them to adapt to changing market conditions or implement changes to operations more readily compared to large firms $[40,41]$.

SMEs are of special interest because they are seen in various roles: being of strategic importance for economic recovery and as a source of disruptive innovation for sustainability transformation [42-44]. There are various arguments for and against their role as drivers of transformations, which cannot be explored here [12, 22-24, $35,36,40,45,46]$. Trends regarding new business models and entrepreneurial orientation in the Netherlands can be observed around the Social Enterprise

\footnotetext{
${ }^{1}$ A general definition of micro, small and medium-sized enterprises (SMEs) is based on their size in personnel ( $\leq 250$ persons), financial annual turnover ( $\leq € 50$ million) and/or an annual balance sheet total ( $\leq € 43$ million) [26]
} 
concept where it has been most recently discussed in the ministry of economics to introduce a new legal form for this business model (Social Enterprise NL 2015) The dynamic character of SMEs provides the appeal for such an entry point to leverage frontrunner practices and eventually develop epicentres of transition. Recent conceptualizations of the role of sustainability-oriented SMEs (s-o-SMEs) in sustainability transitions and market transformations have identified a recurring trend wherein new market entrants, typically managed by an owner whose personal values are strongly tied to sustainability $[47,48]$, produce sustainability-oriented innovations (SOIs) relevant to either business operations and/or products [21]. The flexibility and lack of existing business models within s-o-SMEs allow for the development and integration of SOIs as a core tenet of the frontrunner SME's identify, filling a market gap with the emergence of a new niche market [42]. These SOIs may then be appropriated by the mainstream market rather easily, a step towards transitioning the market $[44,49]$. However, this branch of study has not been empirically researched to a great extent [18, 50-52].

Despite the flexibility a smaller firm size allows SMEs, there exist characteristics that tend to limit SMEs' capacity to implement environmental and sustainabilityoriented operational improvements. Limited time, capital, personnel and expertise are commonly cited as barriers to the implementation of environmental measures $[53,54]$. Other challenges in meeting environmental goals include the managers' poor environmental training and short-term orientation, the status of the environmental function in the company as a whole, and SMEs' lower capacity to give rise to highly radical innovations $[24,40]$. Also, going it alone, against common practices of the sector, creates barriers to change [55].

Likely as a result of such barriers, SMEs tend to be reactive in terms of meeting environmental regulations or implementing environmental improvements of operations [40], with the exception of the minority of environmentally-based or motivated SMEs which tend to be proactive in environmental improvements [46, 56]. Large firms tend to be more committed to developing environmentally benign operations than their smaller counterparts [24,37]. Even when SMEs are aware of the potential benefits associated with improving business operations or engaging in crafting regulations which would impact them, many are unwilling to explore which measures or assistance could help them to improve sustainable aspects $[23,57,58]$.

\subsection{Motivations for Sustainable Entrepreneurship}

Improving the profitability of firms through the increased efficiency of operations, for instance improving energy efficiency or reducing raw products needed, is commonly cited as a primary rationale for implementing environmental measures $[35,59,60]$. Among typical SMEs - i.e. those who would not qualify themselves as having a "green" business model - improving the workplace for employees, internal management and social responsibility have been identified as subsequent reasons for investing in environmental measures, followed by regulation and market forces [37]. Motivations for investment identified in the literature include government 
policy (both existing and the threat of future regulation), economics, markets, communities and social pressure, attitudes and social values, technological opportunities and technological and organizational capabilities are each factors affecting innovation in cleaner technologies at the firm level [61-63]. Clearly, these motivations have a direct bearing on sustainability governance in urban spaces: municipalities (in partnership with higher levels of government) can, for instance, designate precincts within which sustainability-oriented businesses co-locate, share or provide complementary products, technologies and services, and create a culture of innovation and social responsibility.

External engagement has been roundly identified as a key element for a SMEs' transition towards sustainability $[40,54,64]$. For instance, the dissemination and application of the cleaner production measures among SMEs on the basis of its own economic merits does not easily occur, resulting in the need to support the dissemination of the concept through promotional activities and policy measures [65]. Incentives have also been noted as a significant driver encouraging a SME towards implementing environmental measures [53, 66, 67]. Incentives may be funded at the national level, but may best be rolled out by the urban authorities (such as municipal economic development or engineering departments), which have a closer links to the needs of their constituent businesses. At the same time, local governments may be allies in creating institutional spaces for sustainable SMEs to connect and advance their knowledge on scaling innovation in the city that has more tactical and operational inputs for the longevity and impact of the SMEs next to the legitimacy and support of national level policies and incentives. An example is how public procurement influences sustainable SMEs at local level: when public procurement includes sustainability criteria and criteria on locality, sustainable SMEs in cities may invest in advancing their practices and procedures to be able to apply for procurement posts [68].

Firms in which the owner/manager had long-term focus and sustainability orientation are much more likely to implement environmental measures into their business operations $[35,40,53,69]$. Similarly, in any kind of SME environmentaloutreach program, the involvement of owner/managers of the program significantly increased the likelihood of implementation of sustainability measures, providing a strong rationale for outreach towards their inclusion in setting up such a program [41].

Among those who identify themselves as practitioners of sustainability-driven enterprises (or ecopreneurs), a shared point appears to be a lessened interest in the quantity of business growth per se, and an enhanced interest in the quality of that business growth and its impact upon the supply chains, markets, and industry sectors around it $[56,70]$. In this context, scaling up has an inherent qualitative dimension, and a decoupling of success from growth. Sustainability-driven SMEs act as an investment of the owner/manager's own lives and values, and view their business not just as an income stream but as a vehicle for social change $[46,56]$. Sustainability entrepreneurship in the sense of green businesses effectively seeks to 
commodify owner/manager's personal values, sense of responsibility and desire to provide education and induce social change, with the expectation that there is a market for such a product within society $[56,62,69]$. In actively pursuing a transformative role, businesses can simultaneously help shift the market they operate in as well as transform their own business. In doing so they can actively shape transitions towards sustainability from the bottom up [18].

\section{Implications of small business sustainability entrepreneurship for the governance of urban sustainability transitions}

There appears to be considerable agreement within the literature that, while SMEs may have significant transformative potential, external organizations are instrumental in engaging SMEs towards improving the environmental aspect of their operations. Local urban authorities, where many of the policies to improve sustainability will be implemented, often rely on external organizations to provide advice and assistance to SMEs $[23,54]$. External organizations appear to fall into two groups: (1) intermediaries, organizations such as NGOs which engage with SMEs with the express purpose of improving some aspect of their operations; and (2) networks, collaborative spaces wherein SMEs engage with other organizations and ideas freely evolve. The intention of both is the same, however: to provide SMEs with the knowledge resources and financial capacity to overcome the characteristics that discourage environmental investment $[48,60,67]$. Many SMEs tend to have a reactive position towards environmental initiatives that discourages environmental improvements, spurring the need for external engagement. Specific, targeted outreach strategies may be needed to recruit SMEs into participating in external organizations [58]. Institutional spaces of experimentation like urban living labs, transition labs, co-creation hubs (e.g. Impact Hubs) are new forms of arrangements that offer dialectic and collaborative opportunities between SMEs and other urban actors, in search of new roles, new agendas and new co-created solutions for the governance of sustainability transformations.

At the same time, SMEs are seen as the creativity pools where new ideas, concepts and even business models are first tested and explored. Once involved, ongoing dialogue between program members/officers and SMEs after the implementation of environmental initiatives is likely to result in sustained levels of environmental consciousness and openness for further improvements [60]. Struggles remain, however, with regard to how to mainstream sustainability and low-carbon innovations that work at the urban scale without compromising the business integrity and the sustainability character of the product, concept or idea.

Questions remain with regard to how the different dimensions of value creation are influenced by socio-economic and institutional contexts and whether, in turn, SMEs, when practicing sustainable business, can transform the service market they operate in. As such, we propose the examination of the following dimensions of value creation by SMEs as a way to unpack their transformative potential in cities: 
the degree of localization of markets, the establishment of new social relations and social configurations (e.g. prosumerism), the closing of resource flows (enabling circular economy), the downscaling of resource consumption and resource footprint (due to reducing resource imports), the advocacy and showcasing of improved labour conditions and creativity for sustainability in the business sector, and the democratization of low-carbon retrofitting of infrastructures.

Intermediaries and networks/collaborative spaces may be crucial tools in the effective governance of sustainability transitions, particularly in urban spaces. It is here that dialogue can effectively be fostered and trust built. Ultimately, both scholars and practitioners require a better understanding of the favourable conditions that might activate the transformative potential of SMEs, and trigger sustained shifts toward sustainable development paths.

\section{References}

1. Westley, F., P. Olsson, C. Folke, T. Homer-Dixon, H. Vredenburg, D. Loorbach, J. Thompson, M. Nilsson, E. Lambin, J. Sendzimir, B. Banerjee, V. Galaz, and S. van der Leeuw, Tipping toward sustainability: emerging pathways of transformation. Ambio, 2011. 40: p. 762-780.

2. Leach, M., J. Rockström, P. Raskin, I. Scoones, A. Stirling, A. Smith, J. Thompson, E. Millstone, A. Ely, and E. Arond, Transforming innovation for sustainability. Ecology and Society, 2012. 17(2): p. 11.

3. Kates, R., W.C. Clark, R. Corell, J.M. Hall, C.C. Jaeger, I. Lowe, J.J. McCarthy, H.-J. Schellnhuber, B. Bolin, N.M. Dickson, S. Faucheux, G.C. Gallopin, A. Gruebler, B. Huntley, J. Jager, N.S. Jodha, R.E. Kasperson, A. Mabogunje, P. Matson, H. Mooney, B. Moore III, T. O'Riordan, and U. Svedin, Sustainability Science. Science, 2001. 292(5517): p. 641-642.

4. Young, O.R., F. Berkhout, G.C. Gallopin, M. Janssen, E. Ostrom, and S. van der Veeuw, The globalization of social-ecological systems: an agenda for scientific research. Global Environmental Change, 2006. 16(304-316).

5. O'Brien, K., Global environmental change III: closing the gap between knowledge and action. Progress in Human Geography, 2012. 37(4): p. 587596.

*6. Pereira, L., T. Karpouzoglou, S. Doshi, and N. Frantzeskaki, Organising a safe space for navigating social-ecological transformations to sustainability. 
International journal of environmental research and public health, 2015. 12(6): p. 6027-6044.

Transformative change is positioned as a modern imperative to improve human wellbeing and reduce economic inequality globally while remaining within ecological 'planetary boundaries'. The paper argues that stronger transdisciplinary collaboration between sustainability transitions and resilience research areas is needed to support experimentation and multi-stakeholder learning. A set of guiding principles is developed for the design of a 'safe operating space' for the planet: 1 . emancipation and empowerment, 2. ensuring reflexivity, 3. knowledge co-creation, 4. transformative learning, 5 . nurturing innovations.

**7. Pelling, M., K. O'Brien, and D. Matyas, Adaptation and transformation. Climatic Change, 2015. 133(113-127).

The authors define transformation as non-linear or radical shifts in culture, norms, development, or risk management. They explore the advantages and disadvantages of transformation over incremental action and resistance, and identify the time scales, institutions, and actors groups.

8. Jakob, M. and J. Hilaire, Climate science: Unburnable fossil-fuel reserves. Nature, 2015. 517: p. 150-152.

9. O'Brien, K., Global environmental change II: from adaptation to deliberate transformation. Progress in Human Geography, 2012. 36(5): p. 667-676.

10. Burch, S., A. Shaw, A. Dale, and J. Robinson, Triggering transformative change: A development path approach to climate change response in communities. Climate Policy, 2014. 14(4): p. 467-487.

**11. Bulkeley, H., M. Breitfuss, L. Coenen, N. Frantzeskaki, L. Fuenfschilling, M. Grillitsch, C. Hartmann, A. Kronsell, K. McCormick, S. Marvin, Q. Mai, A. Sauer, F. van Steenbergen, and Y. Voytenko, Theoretical Framework Working Paper on Urban Living Labs and Urban Sustainability Transitions. 2015, Lund University: Lund.

The authors develop a conceptual framework for exploring the role that 'urban living labs' might play in purposefully fostering learning on sustainability in urban spaces. Urban living labs are deeply place-based, involve the participation of multiple actors (including businesses), and can create solutions that may be transferred to other contexts. 
12. Burch, S., H. Schroeder, S. Rayner, and J. Wilson, Novel multi-sector networks and entrepreneurship in Metro Vancouver: A study of small business as an emerging non-state actor on climate change mitigation. Environment and Planning C, 2013. 31(5): p. 822-840.

13. Schroeder, H., S. Burch, and S. Rayner, Novel multi-sector networks and entrepreneurship in urban climate change governance. Environment and Planning C, 2013. 31(5): p. 761-768.

14. Biermann, F., M. Betsill, J. Gupta, N. Kanie, L. Lebel, D. Liverman, H. Schroeder, and B. Siebenhuener, Earth System Governance: People, Places, and the Planet; Science and Implementation Plan of the Earth System Governance Project, in Earth System Governance Project Report No. 1.2009.

15. Loorbach, D., Transition management for sustainable development: A prescriptive, complexity-based governance framework. Governance: An International Journal of Policy, Administration, and Institutions, 2010. 23(1): p. 161-183.

16. Frantzeskaki, N., D. Loorbach, and J. Meadowcroft, Governing transitions to sustainability: transition management as a governance approach towards pursuing sustainability. International Journal of Sustainable Development, 2012. 15: p. 19-36.

17. Smith, A. and A. Stirling, The politics of social-ecological resilience and sustainable socio-technical transitions. Ecology and Society, 2010. 15(1): p. 11 [online].

**18. Loorbach, D. and K. Wijsman, Business transition management: exploring a new role for business in sustainability transitions. Journal of Cleaner Production, 2013. 45: p. 20-28.

This paper argues that fundamental societal changes are demanding more than simple corporate social responsibilities from businesses, and these changing conditions will award a competetive advantage to those that address environmental and social impacts.

19. Lemos, M.C. and A. Agrawal, Environmental governance. Annual Review of Environment and Resources, 2006. 31: p. 297-325.

*20. Driessen, P.P.J., J. Behagel, D. Hegger, H. Mees, L. Almesjö, S. Andresen, F. Eboli, S. Helgenberger, K. Holländer, L. Jacobsen, M. Järvelä, J. Laessoe, S. Oberthür, D. Avelar, U. Brand, A. Brunnengräber, H. Bulkeley, D. Compagnon, 
S. Davoudi, H. Hackmann, J. Knieling, C. Larrue, B.-O. Linnér, O. Martin, K. O'Brien, S. O'Neill, M. Van Rijswick, B. Siebenhuener, K. Termeer, and A. Verbruggen, Societal transformations in the face of climate change: research priorities for the next decade. JPI Climate [online], 2015.

The authors argue that a more prominent role for social science is needed to improve understand societal consequences of climate change and to inform adaptation and mitigation efforts. They also suggest that a deeper understanding must be gained of ways that the abilities of societies to respond to climate change is enabled or constrained by other social and political dynamics.

21. Halila, F., Networks as a means of supporting the adoption of organizational innovations in SMEs: the case of Environmental Management Systems (EMSs) based on ISO 14001. Corporate Social Responsibility and Environmental Management, 2007. 14(3): p. 167-181.

**22. Klewitz, J. and E.G. Hansen, Sustainability-oriented innovation of SMEs: a systematic review. Journal of Cleaner Production, 2014. 65: p. 57-75.

This paper integrates literature on SMEs and sustainability-oriented innovations (SOIs) through a systematic literature review. It develops a framework for categorizing and identifying how strategic sustainability behaviours can lead to innovations in SMEs. The authors also propose that external actors (e.g. customers, authorities, research institutes) can increase SME's capacity for sustainability innovations.

23. Bradford, J. and E.D. Fraser, Local authorities, climate change and small and medium enterprises: identifying effective policy instruments to reduce energy use and carbon emissions. Corporate Social Responsibility and Environmental Management, 2008. 15(3): p. 156-172.

24. Aragón-Correa, J.A., N. Hurtado-Torres, S. Sharma, and V.J. Garcia-Morales, Environmental strategy and performance in small firms: A resource-based perspective. Journal of environmental management, 2008. 86(1): p. 88-103.

25. Martín-Tapia, I., J.A. Aragón-Correa, and A. Rueda-Manzanares, Environmental strategy and exports in medium, small and micro-enterprises. Journal of World Business, 2010. 45(3): p. 266-275. 
26. EC, Commission Recommendation of 6 May 2003 concerning the definition of micro, small and medium-sized enterprises. Official Journal of the European Union, 2003: p. 36-41.

27. North, P., The business of the Anthropocene? Substantivist and diverse economies perspectives on SME engagement in low carbon transitions. Progress in Human Geography, 2015. Online: p. 1-18.

28. Barnes, T.J., Retheorizing economic geography: From the quantitative revolution to the 'cultural turn'. Annals of the Association of American Geographer, 2001. 91(3): p. 546-565.

29. Turnheim, B., F. Berkhout, F. Geels, A. Hof, A. McMeekin, B. Bykvist, and D. van Vuuren, Evaluating sustainability transitions pathways: Bridging analytical approaches to address governance challenges. Global Environmental Change, 2015. 35: p. 239-253.

30. Markard, J., R. Raven, and B. Truffer, Sustainability transitions: An emerging field of research and its prospects. Research Policy, 2012. 41(6): p. 955-967.

31. Smith, A., J.-P. Voß, and J. Grin, Innovation studies and sustainability transitions: The allure of the multi-level perspective and its challenges. Research Policy, 2010. 39(4): p. 435-448.

32. Geels, F.W., Technological transitions as evolutionary reconfiguration processes: a multi-level perspective and a case-study. Research Policy, 2002. 31(8-9): p. 1257-1274.

**33. Shaw, A., S. Burch, F. Kristensen, J. Robinson, and A. Dale, Accelerating the sustainability transition: Exploring synergies between adaptation and mitigation in British Columbian communities. Global Environmental Change, 2014. 25: p. 41-51.

This paper examines the ingredients of transformative change in an urban context, and suggests that a sustainability (rather than climate-centric) framing may trigger the development and uptake of more radical solutions. Businesses are identified as key actors in the multi-level governance or urban sustainability.

34. Burch, S., In pursuit of resilient, low-carbon communities: An examination of barriers to action in three Canadian cities. Energy Policy, 2010. 38(12): p. 7575-7585. 
35. Bos - Brouwers, H.E.J., Corporate sustainability and innovation in SMEs: evidence of themes and activities in practice. Business Strategy and the Environment, 2010. 19(7): p. 417-435.

36. Moore, S.B. and S.L. Manring, Strategy development in small and medium sized enterprises for sustainability and increased value creation. Journal of cleaner production, 2009. 17(2): p. 276-282.

37. Masurel, E., Why SMEs invest in environmental measures: sustainability evidence from small and medium-sized printing firms. Business Strategy and the Environment, 2007. 16(3): p. 190-201.

38. Boiral, O., C. Baron, and O. Gunnlaugson, Environmental leadership and consciousness development: A Case study among Canadian SMEs. Journal of business ethics, 2014. 123(3): p. 363-383.

39. Jämsä, P., J. Tähtinen, A. Ryan, and M. Pallari, Sustainable SMEs network utilization: the case of food enterprises. Journal of Small Business and Enterprise Development, 2011. 18(1): p. 141-156.

40. del Brío, J.Á. and B. Junquera, A review of the literature on environmental innovation management in SMEs: implications for public policies. Technovation, 2003. 23(12): p. 939-948.

41. Hansen, E.G. and J. Klewitz, Publicly mediated inter-organizational networks: a solution for sustainability-oriented innovation in SMEs, in Entrepreneurship, innovation and sustainability, M. Wagner, Editor. 2012, Greenleaf: Sheffield.

42. Hockerts, K. and R. Wüstenhagen, Greening Goliaths versus emerging DavidsTheorizing about the role of incumbents and new entrants in sustainable entrepreneurship. Journal of Business Venturing, 2010. 25(5): p. 481-492.

43. Schaltegger, S. and M. Wagner, Sustainable entrepreneurship and sustainability innovation: categories and interactions. Business Strategy and the Environment, 2011. 20(4): p. 222-237.

44. OECD, The Impact of the Global Crisis on SME and Entrepreneurship Financing and Policy Responses. 2009, Organization for Economic Cooperation and Development: Paris.

45. Gebauer, J. and H. Mewes, Qualität und Suffizienz in stabilitätsorientierten $K M U$. UmweltWirtschaftsForum, 2015. 23(1-2): p. 33-40. 
46. Walley, E. and D.W. Taylor, Opportunists, Champions, Mavericks...? Greener Management International, 2002. 2002(38): p. 31-43.

47. Beveridge, R. and S. Guy, The rise of the eco-preneur and the messy world of environmental innovation. Local Environment: The International Journal of Justice and Sustainability, 2005. 10(6): p. 665-676.

48. Lehmann, M., Government-business relationships through partnerships for sustainable development: the green network in Denmark. Journal of Environmental Policy and Planning, 2006. 8(3): p. 235-257.

49. Smith, A., Green niches in sustainable development: the case of organic food in the United Kingdom. Environment and Planning C: Government \& Policy, 2006. 24(3): p. 439-458.

*50. Hörisch, J., The Role of Sustainable Entrepreneurship in Sustainability Transitions: A Conceptual Synthesis against the Background of the Multi-Level Perspective. Administrative Sciences, 2015. 5(4): p. 286-300.

By synthesizing the literatures of transitions and sustainability entrepreneurship, this paper helps to address the common criticism of transitions studies that the agency of actors is neglected, leaving gaps in our understanding of capacities and power dynamics. The author highlights the clash between the notion of degrowth (heralded by some as a path to sustainability) and the need for growth of sustainability-oriented SMEs in order to trigger a broader transformation.

51. Bergset, L. and K. Fichter, Green start-ups - a new typology for sustainable entrepreneurship and innovation research. Journal of Innovation Managemetn, 2015. 3(3): p. 118-144.

52. Gibbs, D., Sustainability entrepreneurs, ecopreneurs and the development of a sustainable economy. Greener Management International, 2008. 55: p. 63-78.

53. Granek, F. and M. Hassanali, The Toronto Region Sustainability Program: insights on the adoption of pollution prevention practices by small to mediumsized manufacturers in the Greater Toronto Area (GTA). Journal of Cleaner Production, 2006. 14(6): p. 572-579.

54. Hansen, E.G. and J. Klewitz, Publicly mediated inter-organizational networks: a solution for sustainability-oriented innovation in SMEs. Entrepreneurship, innovation and sustainability. Greenleaf, Sheffield, 2012: p. 254-278. 
55. Chu, S.Y. and H. Schroeder, Private governance of climate change in Hong Kong: an analysis of drivers and barriers to corporate action. Asian Studies Review, 2010. 34(3): p. 287-308.

56. Rodgers, C., Sustainable entrepreneurship in SMEs: a case study analysis. Corporate Social Responsibility and Environmental Management, 2010. 17(3): p. 125-132.

57. Lefebvre, L.A. and S. Talbot, Life cycle design approach in SMEs. The International Journal of Life Cycle Assessment, 2001. 6(5): p. 273-280.

58. Setzer, J. and R. Biderman, Increasing participation in climate policy implementation: a case for engaging SMEs from the transport sector in the city of São Paulo. Environment and Planning C: Government and Policy, 2013. 31(5): p. 806-821.

59. Friedman, A.L., S. Miles, and C. Adams, Small and medium-sized enterprises and the environment: evaluation of a specific initiative aimed at all small and medium-sized enterprises. Journal of Small Business and Enterprise Development, 2000. 7(4): p. 325-342.

60. Klewitz, J., A. Zeyen, and E.G. Hansen, Intermediaries driving eco-innovation in SMEs: a qualitative investigation. European Journal of Innovation Management, 2012. 15(4): p. 442-467.

61. Montalvo, C., General wisdom concerning the factors affecting the adoption of cleaner technologies: a survey 1990-2007. Journal of Cleaner Production, 2008. 16(1): p. S7-S13.

62. Williams, S. and A. Schaefer, Small and medium - sized enterprises and sustainability: Managers' values and engagement with environmental and climate change issues. Business Strategy and the Environment, 2013. 22(3): p. 173-186.

63. Zorpas, A., Environmental management systems as sustainable tools in the way of life for the SMEs and VSMEs. Bioresource technology, 2010. 101(6): p. 1544-1557.

64. Loorbach, D., J.C. van Bakel, G. Whiteman, and J. Rotmans, Business strategies for transitions towards sustainable systems. Business Strategy and the Environment, 2010. 19(2): p. 133-146. 
65. Luken, R.A. and J. Navratil, A programmatic review of UNIDO/UNEP national cleaner production centres. Journal of Cleaner Production, 2004. 12(3): $\mathrm{p}$. 195-205.

66. Clement, K. and M. Hansen, Financial incentives to improve environmental performance: a review of Nordic public sector support for SMEs. European Environment, 2003. 13(1): p. 34-47.

67. Parker, P. and I.H. Rowlands, City partners maintain climate change action despite national cuts: residential energy efficiency programme valued at local level. Local Environment, 2007. 12(5): p. 505-517.

68. Walker, H. and L. Preuss, Fostering sustainability through sourcing from small businesses: public sector perspectives. Journal of Cleaner Production, 2008. 16(15): p. 1600-1609.

69. Anderson, A.R., Cultivating the Garden of Eden: environmental entrepreneuring. Journal of Organizational Change Management, 1998. 11(2): p. $135-144$.

70. Bocken, N.M.P. and S.W. Short, Towards a sufficiency-driven business model: Experiences and opportunities. Environmental Innovation and Societal Transitions, 2016. 18: p. 41-61. 